\title{
Beyond Reasonable Doubt: An Abductive Dilemma in Criminal Law
}

\author{
JOHN WOODS
}

\author{
Department of Philosophy \\ University of British Columbia \\ 1866 Main Mall \\ Vancouver B.C. \\ CANADA V6T1Z1 \\ jhwoods@interchange.ubc.ca \\ Web-page: www.johnwoods.ca
}

\author{
Department of Computer Science \\ King's College \\ Strand \\ London \\ WC2R 2LS \\ $U K$ \\ woodsj@dcs.kcl.ac.uk
}

\begin{abstract}
In criminal cases at common law, juries are permitted to convict on wholly circumstantial evidence even in the face of a reasonable case for acquittal. This generates the highly counterintuitive-if not absurdconsequence that there being reason to think that the accused didn't do it is not reason to doubt that he did. This is the no-reason-todoubt problem. It has a technical solution provided that the evidence on which it is reasonable to think that the accused didn't do it is a different subset of the total evidence from that on which there is no reason to doubt that he did do it. It lies in the adversarial nature of criminal proceedings in the common law tradition that the subsets of the total evidence on which counsel base their opposing arguments are themselves different from and often incompatible with one another. While this solves the no-reason-to-doubt problem, it does so at the cost of triggering a second problem just as bad. It is the no-rival problem, according to which incompatible theories of the case based on incompatible subsets of the evidence cannot be rivals of one another. If neither party's case contradicts the other's then, by the burden of proof requirement, criminal convictions are impossible. Once having generated the dilemma, the object of the paper is to determine how it might be escaped.
\end{abstract}

Résumé: Dans les procès de droit coutumier, un jury peut reconnaître quelqu'un de coupable en se fondant entièrement sur des preuves indirectes, même à l'encontre d'arguments raisonnables pour un acquittement. Ceci implique la conséquence contre-intuitive - sinon absurde - que des raisons qui appuient la conclusion qu'un accusé n’a pas commis un délit ne suffisent pas pour douter qu'il l'ait commis. Ceci est le problème d'aucune-raison-de-douter. Il a une solution technique: l'appui sur lequel il est raisonnable de penser que l'accusé n'a pas commis de délit est un sous-ensemble différent de la totalité des preuves sur lesquelles il n’y a aucune raison de douter que l'accusé ait commis un délit. C'est dans la nature antagoniste de la tradition des procès de droit coutumier que les sous-ensembles de la totalité des preuves sur lesquelles la défense avance ses arguments opposés sont eux-mêmes différents et souvent incompatibles l'un l'autre. Bien que ceci résolve le problème d'aucune-raison-de-douter, il déclenche un problème aussi sérieux. C'est le problème d'aucun-rival, selon lequel les théories incompatibles d'un procès fondées sur les sous-ensembles incompatibles de preuve ne peuvent pas rivaliser une avec l'autre. Si l'argument d'un parti ne contredit pas celui de l'autre, alors selon les exigences de la charge de preuve, un jugement judiciaire final est impossible. Après avoir exposé ce dilemme, l’objectif de cet article est de déterminer comment on pourrait le l'éliminer.

Keywords: abduction, circumstantial evidence, evidence, evidence-filtrations, guessing, ignorance-preserving inference, inference to the best explanation, hypothesis of the case, reasonable doubt, reasonable hypothesis, theory of the case, theory of the evidence. 


\section{Reasonability without reasonable doubt}

In the common law tradition, a theory of the case is an inference to the hypothesis that best explains the evidence. The prosecutor's theory of the case is that what best explains the evidence is that the accused is guilty as charged. The defense's theory of the case is that that which best explains the evidence is incompatible with the hypothesis of guilt. One of the principal duties of a juror is to assess the respective merits of the parties' theories of the case. Inference to the best explanation is perhaps the most common, and most intuitive, form of abductive reasoning. Peirce noted a long time ago that abduction is a kind of guessing (Peirce, 1931-1958, 5.172). In as much as it is Peirce who introduced the term "abduction" to cover regressive inferences of this kind, we shouldn't be too quick in dismissing the guessing feature that he claims for it. Of course, there are costs involved in our staying with the Peircian conception of abduction. One is that, on the face of it, no theory of the case can satisfy the criminal standard of proved beyond a reasonable doubt. For how can guessing at a proposition ever amount to a proof of it? ${ }^{1}$ In (Woods, 2007b), I have explored ways in which this difficulty might be resolved. In the present paper, I want to turn my attention to some other difficulties that arise in the abductive environments of criminal jurisprudence.

The proof standard itself is subject to constraints that appear to damage what might be called the "epistemic legitimacy" of criminal proceedings, generating verdicts that are either factually untrue or factually unsupported. ${ }^{2}$ It is widely conceded that, while a trial has the twin objectives of truth and justice, there are various respects in which the goal of justice takes precedence over the commitment to truth. ${ }^{3}$ Even so, what the problems to be discussed here suggest is that the law's epistemic shortfalls compromise not only the duty to get at the truth of things but also the duty to render justice. In this section and the one to follow I shall attempt to expose a pair of these difficulties. In so doing, it will become apparent that the two problems together create at least the strong appearance of a dilemma concerning how criminal verdicts are reached. In section 3 , I will consider ways in which the dilemma might be escaped. In section 4, I examine implications for the structure of jury deliberations.

\footnotetext{
${ }^{1}$ In (Gabbay and Woods, 2005) and (Gabbay and Woods, 2006) it is proposed that, unlike deduction, which is truth-preserving, and induction, which is likelihoodenhancing, abduction is ignorance-preserving. (Goddu, 2005) challenges this as stipulation without benefit of supporting argument (p. 293). This is not the place to consider Goddu's objection in any detail. Suffice it to say here that by far the majority of legal verdicts are indeed arrived at without knowing whether the accused is guilty as charged. What the criminal proof standard does not require is knowledge of guilt.

${ }^{2}$ See (Laudan, 2006) for a detailed and vigorously argued case to this same effect.

${ }^{3}$ It is taken as a matter of basic justice that procedures that minimize false convictions are necessary even at the cost of an increase in the acquittal of guilty persons.
} 


\section{John Woods}

The first half of the purported dilemma arises most naturally in the context of cases that are based solely on circumstantial evidence. The question of whether convictions are allowed in such circumstances is attended by two widely-shared and incompatible common sense misconceptions. One is that merely circumstantial evidence is too weak to meet the criminal standard of proof beyond a reasonable doubt. The other is that that-short of certainty-a prosecutor's theory of the case cannot meet the standard if there exists a rival theory of the case that is reasonable. In fact, however, both assumptions are false. Concerning the presumed inadequacy of circumstantial evidence,

History is replete with examples of convictions based exclusively on circumstantial evidence (Klotter, 1992, p. 69, emphasis added).

Moreover, in an American case from 1969,

The trial judge properly instructed the jury that 'the law makes no distinction between direct and circumstantial evidence but simply requires that the reasonable doubt ${ }^{4}$ [if it exists] should be drawn from all the evidence of the case', including 'such reasonable inferences as seem justified in the light of your own experiences' (Klotter, 1992, p. 68).

The second common sense assumption is well-summed up in a California ruling:

However, a finding of guilt as to any crime may not be based on circumstantial evidence unless the proved circumstances are not only (1) consistent with the theory that the defendant is guilty of the crime, but (2) cannot be reconciled with any other rational conclusion .... Also, if the circumstantial evidence permits two reasonable interpretations, one of which points to the defendant's guilt and the other to innocence, you must adopt that interpretation that points to the defendant's innocence, and reject that interpretation that points to guilt (CALJIC 2.01), emphases added). ${ }^{5}$

Although this ruling still stands in state courts in California, in 1954 the U.S. Supreme Court struck it down for use in federal courts. ${ }^{6}$ A similar refusal is forcefully made by the Indiana Court of Appeals in a 1978 case. As reported by Klotter, the Indiana ruling provides that

\footnotetext{
${ }^{4}$ Quoted from (Laudan, 2006, p. 82).

${ }^{5}$ Quoted from (Laudan, 2006, p 82).

${ }^{6}$ (Laudan, 2006, p. 82).
} 
Convictions should not be overturned simply because this court determined that the circumstances do not exclude every reasonable [acquitting] hypothesis of [the] evidence (Klotter, 1992, p. 69).

The offence to common sense is obvious. A criminal conviction may be allowed to stand even when there exists a theory of the case that calls for acquittal and the theory is reasonable. The problem arises from the following pair of facts.

Fact 1: By the proof standard, a criminal conviction requires that the evidence show the accused's guilt beyond a reasonable doubt.

Fact 2: By the rulings presently in view, a criminal conviction is permitted even when there exists a reasonable case for acquittal.

If there exists a reasonable case for acquittal then, by common sense, that very fact constitutes a reasonable doubt of guilt. This is precisely the upshot of CAJIC 2.01, but it is precisely this that the Supreme Court overturned federally and the Indiana Court of Appeal expressly disavowed.

How can we have it that reasonable grounds for thinking an accused not guilty not constitute a reasonable doubt of his guilt? How is a judgement of bald inconsistency to be averted here? ${ }^{7}$ It is important to emphasize that what the criminal standard does not provide for is that a verdict to convict is sound if the case for conviction is more reasonable than the case for acquittal, even if the case for acquittal is also reasonable. What the standard also requires is that the reasonableness of the case for acquittal not, just so, constitute a reason to doubt the case for conviction. Let us set this out schematically.

1. G explains $\mathrm{E} / \therefore \mathrm{G}$ theory of the case)

2. $\sim \mathrm{G}$ explains $\mathrm{E} / \therefore \sim \mathrm{G}$ of the case)

3. Abductive inference (1) is reasonable

4. Abductive inference (2) is reasonable

5. Inference (1) is more reasonable than abductive inference (2)

6. The cogency of (2) need not expose (criminal jurisprudence) the hypothesis $\mathrm{G}$ to a reasonable doubt (the prosecution's

(the defense's theory

(hypothesis)

(hypothesis)

(hypothesis)

$$
\text { the hypothesis } G \text { to a reasonable doubt }
$$

A 1978 ruling by the First Federal Appeals Court captures this reasoning almost perfectly:

\footnotetext{
${ }^{7}$ See Holland v. U.S. (1954) for the wry observation that "instruction on circumstantial evidence is confusing and incorrect."
} 


\section{John Woods}

The prosecution may prove its case by circumstantial evidence, and it need not exclude every reasonable hypothesis of innocence so long as the total evidence permits a conclusion of guilt beyond a reasonable doubt. (U.S. v. Gabriner, 571F.2d 48, at 50, [1 ${ }^{\text {st }}$ Cir., 1978].)

It is a sentiment echoed in the Court's subsequent ruling of 1983:

The trier of fact is free to choose among various reasonable constructions of the evidence. ${ }^{8}$

I daresay that there will be some people for whom the sheer counterintuitiveness of this, the no-reason-to-doubt problem, is a standing invitation to ambiguate. Perhaps this is right. Perhaps there are different senses of "reasonable" and "reason" that make it reasonable to think that the accused didn't do it without constituting a reason to doubt that he did. However, in the absence of independent specification of these senses, I proposed to leave the ambiguation option untouched. That is to say, I shall take it as a tactical matter that there is no ambiguity attaching to these occurrences of "reasonable" and "reason". If this is right, we appear to be left with just two options. One is to concede that the criminal proof standard is incoherent, hence massively unjust. The other is to search for a solution elsewhere.

\section{The no-rival problem}

The common law is an adversarial system. This carries direct consequences for how evidence is arrived at. In a word, evidence is generated tendentiously. Whether a witness will be heard at all is a matter of counsel's decision and the judge's acquiescence, and what a witness testifies to is tightly constrained by the questions put to him by counsel.

This element of tendentiousness in the presentation of evidence is crucially important in the common law tradition. Evidence is led by counsel for the opposing sides. What a prosecutor will want to place before a jury is commonly quite different from what the defense will wish the jury to hear. It lies in the adversarial nature of proceedings at common law not only that opposing counsel will usually offer rival theories of the evidence, but also that they will introduce rival bodies of evidence. There is a nice reciprocity in this, in as much as the evidence selected by respective counsel to attach his own theory to will be evidence that best fits the theory. We may take it then that the selfservingness that attaches to the use of evidence has two interlocking tendrils. The evidence that a lawyer generates is tailored to fit his preselected hypothesis of the case, and the selection from the totality of what

${ }^{8}$ U.S. v. Thornley, 707 F. 2d 622, at 625 (1 ${ }^{\text {st }}$ Cir., 1983). 
is heard that a lawyer cites as the evidence to be explained is picked for its explanatory susceptibility to that same hypothesis. When it comes to evidence, opposing counsel are cherry-pickers. ${ }^{9}$

We have it, then, that for wide ranges of cases, when opposing counsel present their respective theories of the evidence, not only are their explanatory hypotheses different-guilty in the one case, not guilty in the other-but the evidence that their respective hypotheses are offered as best explaining are incompatible subsets of the total testimony heard. The basic structure of this putative rivalry is this. Putting $G$ for the hypothesis of guilty as charged and $\sim G$ for the hypothesis of not guilty as charged, and putting $E$ and $E^{*}$ for counsel's different and usually incompatible subsets of the total evidence, the prosecution's theory of the case is that

\section{$G$ best explains $E$}

whereas the defense's theory of the case is that

\section{$\sim G$ best explains $E^{*}$.}

On the face of it, this is ludicrous. It makes it impossible to see in what this rivalry could consist, and in particular how the prosecution's case overrides the defense's case. That being so, it would appear that convictions at the criminal bar are impossible to achieve. Let us call this the no-rival problem. Left unsolved, the no-rival problem makes any criminal trial a travesty of justice.

\section{A dilemma?}

A solution to the no-reason-to-doubt problem is required lest the criminal proof standard fall into incoherence in those numerous cases in which the evidence is solely circumstantial and there exist reasonable theories of it by both sides. A solution to this problem is achievable by abandoning the assumption that the competing theories of the case are grounded in identically the same evidence. But if this is done, then the parties' apparently opposing theories of the case lose their status as rivals. In particular, the case for acquittal cannot override the case for conviction, just as the case for conviction cannot be undone by the case for acquittal. Since the respective theories of the case leave one another untouched, there is as much reason to acquit as to convict, leaving the consequence that the criminal proof standard cannot be met in any such case. But in as much as such cases are the norm, we also have it as a norm that the proof standard can't be met; that is, that by and large it can't be met. But an unmeetable proof standard is legally incoherent.

\footnotetext{
${ }^{9}$ This kind of one-sidedness in argumentation is discussed in (van Laar, 2007).
} 
This, then, is our dilemma. The no-reason-to-doubt problem makes for judicial incoherence. Its solution is of a kind that takes us out of the frying pan of the no-reason-to-doubt problem into the fire of the no-rival problem, which generates incoherencies of its own.

Actual practice indicates a way out of our dilemma, and a good thing too. If juries were required to base their decisions on opposing counsel's versions of the evidence, $\mathrm{E}$ and $\mathrm{E}^{*}$, not only would they be landed in the no-rival problem, but much more often than not they would be subject to the illogical duty of accepting incompatible subsets of the total evidence heard. Since, as already noted, counsel lead and rebut evidence tendentiously, that is, with a view to its fitting their own respective pre-determined theories of the case, what reason is there to suppose that their respective summations would be any the less selfserving and selective? As it happens, what a juror is in fact required to consider is whether $G$ is the best explanation of that subset of the total evidence that he himself selects, that he himself picks out as the grounds upon which his assessment of $G$ must rest. Although it cannot be guaranteed in advance that a juror's evidence will never be identical to that of the one counsel or the other, it is empirically evident that a juror will nearly always put into play a third subset of the total. ${ }^{10}$ Either way, the juror will have made the evidence on which he himself will proceed abductively "his own”.

The story of how a juror goes about filtering the evidence into a basis for his own determinations is a highly complex and epistemologically vexed one ([Woods, 2007a, 2007b), for which I lack the space here. ${ }^{11}$ Suffice it to say that the mere fact that jurors produce

\footnotetext{
${ }^{10}$ Although it is equally common for these different subsets also to overlap to some extent.

${ }^{11}$ We note in passing some of the difficulties that filtration has to contend with. One is that, in the general case, witnesses and jurors are strangers to one another, with no independent access to the track record of these witnesses' honesty and reliability. It is true that jurors can be governed by requisite default assumptions such as that people in general are truthful in general. But the assumption is to some degree called into question by the fact that, owing to the incoherencies that afflict the total testimony, some of these witnesses are lying or honestly mistaken. But then the question is: Who are these jurors to believe? Part of what guides jurors in the solution of such problems is the plausibility of what they hear. But this, too is modified guidance at best. For some of what they hear is highly implausible, and yet might be accepted on the basis of the plausibility of the witness who attests to it. All this occasions a serious challenge to the would-be logician of legal reasoning. All the going theories of plausibility presuppose the appraiser's independent access to a witness's "reliability” index (see, e.g., [Rescher, 1976]). And, while there is little doubt that jurors (and the rest of us) implicitly recognize a distinction between the plausibility of what is said and the plausibility of him who says it, no known theory of plausibility satisfactorily elucidates the contrast and most don't deal with it at all. It is true, however, that lawyers do discuss a witness's testimony under the heading of "demeanor", that is, their "conduct, bearing, behaviour, delivery, inflexion: in short, anything that characterizes [their] mode of giving evidence but does not appear in a transcript of what [this] actually said” (Bingham, 2006, p. 333). Interestingly, enough, it appears to be a growingly dominant opinion among judges that witness's demeanor is not in fact a particularly reliable indicator of his reliability.
} 
their own filtrations of the evidence provides the technical means of escaping our dilemma. To see how this happens, consider first the noreason-to-doubt problem. In convicting an accused, a juror must find that on the basis of his own filtration of the evidence the accused is guilty beyond a reasonable doubt. If we suppose that, in so determining, he allows that there is a reasonable case for acquittal, then he must acquit unless the case for acquittal attaches to a different filtration of the evidence. In that case the reasonableness of the contrary case is grounded in evidence that the juror doesn't accept or to which he gives insufficient weight to support the rival hypothesis. Since it is routinely the case that in the situation we are presently describing jurors and counsel will be operating with different evidence-filtrations, then it is open to juries to convict even in the face of a reasonable case for acquittal. For now a reasonable case for acquittal is, for any juror intent on conviction, a reasonable explanation-perhaps even the best explanation-of an evidence-filtration that he is unhappy with.

Relief can also be offered to the no-rival problem. Given that nearly always opposing counsel rest their respective pleadings on different and incompatible filtrations of the evidence, this creates a norival problem for counsel. The prosecution's 〈G best explains E; so $G\rangle$ and the defense's $\left\langle\sim G\right.$ best explains $E^{*}$; so $\left.\sim G\right\rangle$ have precisely the logical character imputed by the no-rival problem. It is a problem that would have teeth if the juror's duty were to accept one of these inferences on grounds that it does better, both explanatorily and in relation to the proof standard, than its rival. For if there is no rival, that determination cannot be made. In fact, however, this is not the juror's duty. His duty is not to break an unbreakable tie between prosecution and defense abductions, but rather to determine whether the G-hypothesis is adequately grounded in his own filtration of the evidence, even if should chance to be the case, however rarely, that his own filtration of the evidence is identically the same as that of one or other of the counsel.

\section{Incommensurabilities in the jury room}

The no-rival problem is a kind of incommensurability problem. Where E and $\mathrm{E}^{*}$ are rival filtrations of the evidence, then the claims that $\mathrm{G}$ best explains $E$ and that $\sim G$ best explains $E^{*}$ cannot be rival theories of the evidence. Two things are incommensurable when these are not able to be judged by the same standard. So the betterness of $G$ on $E$ over $\sim G$ on $E^{*}$ is indeed incommensurable. True, $G$ might be a better explanation of $E$

(Bingham, 2006, p. 335). As Lord Bingham of Cornhill remarks, "I ally myself with the doubters" (idem). Perhaps judges, who are experienced in the ways and means of oral testimony have grounds on which to secure this dismissiveness. But for jurors, who in the nature of the criteria for their selection, are rookies, it is hard to see how the factor of speaker-plausibility isn't often significantly in play. 


\section{John Woods}

than $\sim \mathrm{G}$ is of $E^{*}$. But absent an independent assessment of the betterness (i.e., the superior acceptability) of $E$ over $E^{*}$ or of $E^{*}$ over $E$, the two theories of the evidence can't be one another's rivals. That is, $\langle G$ best explains $E$; so $G\rangle$ and $\left\langle\sim G\right.$ best explains $E^{*}$; so $\left.\sim G\right\rangle$ can both be cogent inferences to the best explanation. But they are cogent in relation to different parameters E and E*. They lack a "common standard".

It may strike us as odd, that is, as logically odd, that pleadings at the criminal bar should so routinely lock opposing counsel into such incommensurabilities. Perhaps it is not surprising, then, that-thus positioned-counsels' respective theories of the case are questionbegging and full of straw. ${ }^{12}$ Surprising or not, it doesn't matter. It doesn't matter because it is not the role of counsel to construct an argument that will be accepted by his opponent. Rather his role is to assist the juror in constructing an argument that will be accepted by the juror. To this end, respective counsel will try to "sell” jurors two things. Not only will they press their own theories of the evidence, they will also press their own filtrations of the evidence.

With these things said, an interesting clarification can be made as to how in the individual discharge of their duties jurors acting together generate criminal verdicts. As we have seen, the individual juror has a twofold duty. He must fashion a judgement as to the accused's guilt on the evidence, and he must tie that question to his own filtration of the evidence. In most criminal trials at common law, there are twelve jurors, and in most jurisdictions convictions require the jury's unanimous vote. Since the jury will either acquit or convict, there are two cases to consider. $^{13}$

- The jury acquits. It suffices for acquittal that there be at least one filtration of the evidence, accepted by at least one juror, for whom the hypothesis of guilt is not the best explanation of it, and/or does not meet the proof standard.

- The jury convicts. Here it is required that for each juror there exists a filtration of the evidence, which the juror is satisfied is best explained by the hypothesis of guilt and does so in fulfillment of the proof standard.

The decisional structure of conviction embodies at least the potential for incommensurability. It is possible in principle that, for each of the twelve jurors who vote for conviction, there exists a different and incompatible

\footnotetext{
${ }^{12}$ One begs the question by attributing to one's rival propositions that he has not conceded, is not committed to conceding and would not concede if asked. One commits a straw-man fallacy against another party when one produces an argument from the other party's concessions whose conclusion contradicts a proposition, which although attributed to him, the other party does not hold and is not committed to holding.

${ }^{13}$ Excepting jury deadlock, and verdicts of not-proven, as in the Scottish tradition.
} 
filtration of the evidence on which his vote is grounded. Should this possibility obtain, then the collective decision of the jury is saturated with incommensurability, what with one's juror's $\left\langle\mathrm{G}\right.$ best explains $E_{1}$, so $G\rangle$ incommensurate with each of the other jurors' $\left\langle G\right.$ best explains $E_{i}$, so $\mathrm{G}\rangle$ (where $2 \leq \mathrm{i} \leq 11$ ). Were it the case that in its collective determination a jury is obliged to reach its decision to convict on a common filtration of the evidence, then convictions would rarely be possible. But, as we see, what a decision to convict requires is agreement about guilt, not about the filtrations in which these decisions to convict are grounded. Mitigating these relativities is the sheer endurance of jury deliberations, routinely extending to days and often to weeks. When jurors deliberate, they expose to one another their own respective theories of the case. In so doing, there is some occasion for one juror's theory of the case to help reshape another juror's filtration of the evidence. But there is nothing in what is known empirically about how juries operate that comes close to supporting the suggestion that in the exercise of their collective judgement juries always or even frequently eliminate these evidencefiltration incommensurabilities. There is a telling lesson in this. A verdict to convict requires that all jurors hold a common hypothesis, but it does not require that jurors have a common theory of the case. The consequences for the requirement of jury unanimity are obvious. It provides that unanimity regarding guilt may rest, and often does rest, on inconsistent filtrations of the evidence. This guarantees that at least some of the propositions in which the verdict of guilt is lodged are false. It also means that any juror who votes for conviction on the basis of his own filtration of the evidence is committed to thinking that any vote for conviction that is lodged in a filtration that is incompatible with his own is defective. This too is problematic. It shows that the criminal proof standard is an even more vexed matter than is suggested by our dilemma. But, for want of space, this is a problem for another time.

\section{Acknowledgements}

I wish to record my gratitude to an anonymous referee and the editor of the present issue of this journal for helpful criticisms and suggestions. I have also benefited from discussions or correspondence with the following persons: S.B. Armstrong, Q.C., the late Jonathan Cohen, Maurice Finocchiaro, David Hitchcock, Erik Krabbe, Steven Wexler, C.L. Woods Q.C., Kelly Woods and especially my colleague and collaborator Dov Gabbay. Funds supporting research for this paper derive in part from grants from The Abductive Systems Group at UBC, the Faculty of Arts and Science, University of Lethbridge and the Engineering and Physical Sciences Research Council of the United Kingdon, for which my sincere thanks. I also warmly thank Carol Woods in Vancouver for technical support. 


\section{References}

Bingham, Tom. (2006). "Assessing contentious eyewitness evidence: A judicial review”. In Anthony Heaton-Armstrong, Eric Shepherd, Gisli Gudjonsson and David Wolchover, editors, Witness Testimony: Psychological, Investigative and Evidential Perspectives, pp. 327-345. Oxford: Oxford University Press. First published in 1985

Gabbay, Dov M. and John Woods. (2005). The Reach of Abduction: Insight and Trial, volume 2 of A Practical Logic of Cognitive Systems. Amsterdam: North-Holland.

Gabbay, Dov M. and John Woods. (2006). “Advice on abductive logic”, Logic Journal of IGPL, 14, pp. 189-219.

Goddu, G.C. (2005).“Woods and Gabbay's The Reach of Abduction: Insight and Trial", Informal Logic, 25, 289-294.

Klotter, John C. (1992). Criminal Evidence, $5^{\text {th }}$ edition. Cincinatti, OH: Anderson Publishing.

Laudan, Larry. (2006). Truth, Error and Criminal Law: An Essay in Legal Epistemology, Cambridge and New York: Cambridge University Press.

Loftus, Elizabeth. (1980). Eyewitness Testimony. Cambridge MA: Harvard University Press.

Peirce, C.S. (1931-1958). Collected Works. Eight volumes, edited by Charles Hartshorne, Paul Weiss and Arthur Burks. Cambridge, MA: Harvard University Press.

Rescher, Nicolas. (1976). Plausible Reasoning: An Introduction to the Theory and Practice of Plausible Inference. Assen and Amsterdam: Van Gorcum.

van Laar, Jan Albert (2007). “One-sided arguments”, Synthese, vol. 154, pp. 307-327.

Woods, John. (2007a). "Relevance in the law”. In Damiano Canale and Giovanni Tuzet, editors Inferentialism in Law and Philosophy.

Woods, John. (2007b). “The criminal abduction paradox". In Shahid Rahman et al., editors, Argumentation and Law. Part of the series Logic, Epistemology and the Unity of Science. Amsterdam: Springer Netherlands. 